\title{
The Menstrual Mark: Menstruation as Social Stigma
}

\author{
Ingrid Johnston-Robledo and Joan C. Chrisler
}

\section{INTRODUCTION $^{1}$}

The American artist Vanessa Tiegs (http://menstrala.blogspot.com) and the German artist Petra Paul (http://mum.org/armenpau.htm) are known for collecting their menstrual flow. When they have collected enough, they sprinkle, splash, and brush their blood across their canvases to create beautiful, and intriguing, works of art. Reactions to their work include shock at their audacity, amazement at their creativity, and disgust at their willingness to exhibit one of nature's most stigmatized fluids (www.truenuff.com/forums/showthread.php? 135-Menstrual-Art-by-Vanessa-Tiegs\&p=1371 \&viewfull=1). One journalist (Heath 2007) wondered whether Tiegs' work should more properly be called art or a biohazard. Contemporary artists often aim to shock viewers (Stallabrass 2006), but these artists have a greater goal in mind (Chesler 2006; Cochrane 2009). They seem to want us to ask ourselves why a mundane product of nature is so shocking, given that most women experience the menses and manage their own menstrual flow for decades of their lives. They want us to consider why menstruation, a benign process essential to the production of human life, evokes fear, disgust, and comparison to toxic waste. We believe that viewers of Tiegs' and Paul's art react the way they do because menstrual blood is a stigmatized substance. In this theoretical paper, we review feminist scholarship regarding the attitudes and experiences of predominantly American girls and women to build the argument that menstruation is a source of social stigma for women. All studies cited in this article were conducted with American samples unless otherwise stated. 


\section{What Is STIGMA?}

According to Goffman (1963), the word stigma refers to any stain or mark that sets some people apart from others; it conveys the information that those people have a defect of body or of character that spoils their appearance or identity. The word derives from a practice of the ancient Greeks, who branded criminals and slaves to mark their status. People reacted with disgust when they saw the brands associated with thieves or traitors, and citizens avoided interacting socially with criminals and slaves (Goffman 1963). Goffman $(1963,4)$ categorized stigmas into three types: "abominations of the body" (for example, burns, scars, deformities), "blemishes of individual character" (for example, criminality, addictions), and "tribal" identities or social markers associated with marginalized groups (for example, gender, race, sexual orientation, nationality). Social psychologists have conducted empirical studies of stigmatized conditions to determine which aspects of those conditions are most abhorrent to other people. The key dimensions are: peril (that is, the perceived danger to others; for example, HIV+individuals), visibility (that is, the obviousness of the mark; for example, facial disfigurement), and controllability (that is, how responsible the individual is for the condition, such as whether the mark is congenital, accidental, or intentional; for example, obesity due to a medical condition or treatment vs. obesity due to "letting oneself go") (Crocker, Major, and Steele 1998; Deaux et al. 1995; Frable 1993). People's beliefs about the controllability of a stigmatized condition (for example, homosexuality) are important because they affect how much stigmatized people are disliked and rejected (Dovidio, Major, and Crocker 2000). For example, lesbians and gay men are better liked and more accepted by people who believe that sexual orientation is biologically based rather than freely chosen (Herek 2009).

\section{Menstruation as a Stigmatized Condition}

We argue that menstrual blood is a stigmatizing mark that fits all three of Goffman's categories. Menstrual rituals and hygiene practices imply that, like other bodily fluids (Rozin and Fallon 1987), menstrual blood is considered an abomination. Some have argued that menstrual blood is viewed as more disgusting or aversive than other bodily fluids such as breastmilk (Bramwell 2001) and semen (Goldenberg and Roberts 2004). In some cultures women are believed to be unclean during their menstrual periods, and they must take a ritual bath (for example, the Jewish Mikvah) to purify themselves before they can be intimate with a man (Cicurel 2000; Goldenberg and Roberts 2004). Given aversions to menstrual blood, a stain may be viewed as a blemish on one's character. From a content analysis of advertisements in Australian magazines, Raftos, Jackson and Mannix (1998) concluded that a powerful message these ads send to readers is that leaks of menstrual blood taint women's femininity because, through the proper choice of products, 
she should have kept the evidence of her menses out of sight. Lee (1994) found that $75 \%$ of the young women she interviewed had experienced or were afraid of experiencing leaks during menstruation. She concluded that visible signs of menstruation represent emblems of girls' contamination (Lee 1994). Roberts et al. (2002) were able to demonstrate empirically that even reminders of menstrual blood (for example, tampons) can lead to avoidance and social distancing, which suggests that menstrual blood may serve as a blemish on women's character. Because only girls and women menstruate, menstrual blood also marks a tribal identity of femaleness. When girls reach menarche (that is, experience their first menstruation), parents and others treat them differently than they did before (Lee and Sasser-Coen 1996). Post-menarcheal girls are cautioned about sexuality, told that they are now "grown-up," and urged to act "ladylike" in ways that restrict the freedom of behavior they had enjoyed in the past (Lee and Sasser-Coen 1996). Thus menstruation marks girls and women as different from the normative and privileged male body (Young 2005). Furthermore, if people hold cultural beliefs that the menstrual cycle causes women to be physically (menstrual phase) or mentally (premenstrual phase) disordered, then the stigma of menstruation also marks women as ill, disabled, out-of-control, unfeminine, or even crazy (Chrisler 2008; Chrisler and Caplan 2002).

Menstrual blood also reflects several of the key dimensions of a stigmatized condition. For example, it has been considered perilous-both magical and poisonous (Golub 1992). Many anthropologists have theorized about the origins and purposes of this symbolism, but, according to Buckley and Gottlieb (1988), there are few firmly established anthropological theories about why menstrual blood may have been viewed that way. Perhaps menstruation seemed magical because, before the physiology of the menstrual cycle was understood, individuals did not understand how women who were not wounded could bleed for five days without being seriously weakened or killed. Because men did not experience menses themselves, they must have been afraid of it, perhaps worried that close contact with menstrual blood might do them some physical damage or pollute them by its association with the mysterious female body. Thus, menstruation may have seemed poisonous.

These ideas are not to be dismissed as naïve or primitive; remnants of them persisted into modern times and remain present today. Cultural feminists (for example, Owen 1993; Stepanich 1992; Wind 1995) who advocate the celebration of menstruation with praise to the Moon Goddess continue the idea that menses and magic are connected. As late as the 1920s and 1930s, scientists (see Delaney, Lupton, and Toth 1987) were attempting to demonstrate that menstruating women exuded what were called menotoxins (that is, poisonous elements) in their menstrual blood, perspiration, saliva, urine, and tears. Images in popular culture of premenstrual women as out-of-control and likely at any moment to be verbally abusive or violent reinforce the ancient notion that menstruation constitutes a peril. In the 1990s, in his 
infamous "giraffe hunting" speech, Congressman Newt Gingrich commented that female soldiers do not belong in the trenches during times when they are highly susceptible to infections. His remarks imply that menstruating women somehow poison themselves and weaken their immune systems, but perhaps what really worried him is the idea that premenstrual American female soldiers might be even more dangerous than the enemy to their male comrades (Chrisler and Caplan 2002).

We assert that menstruation is more like a hidden than a visible stigma, but that is because women go to a great deal of effort to conceal it (Oxley 1998). Menstrual hygiene products (for example, tampons, pads) are designed to absorb fluid and odors, not to be visible through one's clothes, to be small enough to carry unobtrusively in one's purse, and to be discretely discarded in a bathroom container (Kissling 2006). It is usually not possible to know for certain that a woman is menstruating unless she says so . . . or unless menstrual blood leaks through her clothes and exposes her then stigmatized condition.

Until recently, menstruation was not controllable. The menstrual cycle is a force of nature; hormone levels ebb and flow in a regular (or irregular) rhythm. Unless women had an illness (for example, anorexia nervosa, polycystic ovary syndrome) or a temporary condition (for example, pregnancy, lactation, the low level of body fat frequently seen in long-distance runners) that halted the menstrual cycle, they could expect to menstruate at a time determined by their particular cycle. With the advent of oral contraceptives in the 1960s, however, scientists proved that menstruation could be controlled. Women have traditionally taken oral contraceptives daily for three weeks, then not taken pills for one week in order to allow for a form of "break-through bleeding" that resembles normal menstruation. However, in recent years continuous oral contraceptives have been marketed to women as a way to avoid menstruation altogether (Johnston-Robledo, Barnack, and Wares 2006). The ads suggest that women have the "freedom" to make a "choice" about whether to menstruate (Johnston-Robledo et al. 2003). However, against a back-drop of cultural messages that women should always be available (for example, to the men and children in their lives) and should avoid, if at all possible, anything that might discomfit others (Chrisler 2008), we might soon reach the point where most people believe that women should eliminate their menstrual cycles unless they are actively trying to become pregnant. This may increase the stigma attached to those who continue to menstruate regularly.

\section{Transmission of Stigma of Menstruation}

Most of the people who react with shock to Tiegs' and Paul's art have probably never been told that menstruation is a stigmatized condition, but their reactions suggest that they "know" it. The stigma of menstruation is 
conveyed to us everyday through a variety of sociocultural routes. For example, negative attitudes toward menstruation and cultural beliefs about menstruating and premenstrual women are transmitted through products and media (for example, advertisements, magazine articles, books, television) we see everyday (Chrisler 2008; Erchull 2010).

Advertisements are cultural artifacts that play an important role in the social construction of meaning (Merskin 1999). Ads for menstrual products have contributed to the communication taboo by emphasizing secrecy, avoidance of embarrassment, and freshness (Coutts and Berg 1993; Delaney, Lupton, and Toth 1987; Houppert 1999; Merskin 1999). Allegorical images, such as flowers and hearts, and blue rather than reddish liquid, have been used euphemistically to promote secrecy and delicacy (Merskin 1999). Ads play on women's fear of being discovered as menstruating because discovery means stigma (Coutts and Berg 1993). With the invention of panty-liners, advertisers began to tell women to use their products every day so that they can feel "confident" that they will always be "fresh" and untainted (Berg and Coutts 1994). When Oxley (1998) questioned 55 British women about their experiences with menstruation, she found that they echoed many of the themes in the ads. They felt self-conscious during the menses, preferred tampons because they are "less noticeable" than pads, believed that menstrual blood is distasteful to self and others, and supported the sex taboo.

Advertisements are not the only form of public discourse about menstruation. Attitudes are also conveyed through books, magazines and newspaper articles, jokes, and other cultural artifacts, such as "humorous" products like greeting cards and refrigerator magnets (Chrisler 2007, 2008). Most of the attitudes these media convey are negative, and together they have constructed a stereotype of menstruating women, especially premenstrual women, as violent, irrational, emotionally labile, out-of-control, and physically or mentally ill. We have seen bumper stickers (for example, "A woman with PMS and ESP is a bitch who knows everything"), buttons (for example, "It's not PMS, I'm always psychotic"), magnets (for example, "Be very careful: I have PMS and a gun"), cartoons, greeting cards, and books (for example, Raging Hormones: The Unofficial PMS Survival Guide, the cover of which pictures actress Joan Crawford as an axe murderer; Chrisler 2002). If this is what people think about women who are menstruating (or about to menstruate), it's no surprise that women try to conceal this stigmatized condition.

The stigmatized status of menstruation may also be transmitted through the educational booklets produced by sanitary napkin and tampon manufacturers; these booklets typically are written by nurses or health educators employed by the companies. We (Erchull et al. 2002) conducted a content analysis of 28 of these booklets, which were published between 1932 and 1997, and we found that the booklets placed much more emphasis on negative than on positive aspects of menstruation. Cramps, moodiness, and leaks were all mentioned frequently, but growing up was the only positive aspect 
mentioned. Descriptions of the menstrual cycle were kept vague for the most part. Estrogen and progesterone were mentioned in fewer than one-half of the booklets. Even the terms menstruation and ovulation were not used in every booklet, and only one booklet (produced by Planned Parenthood, not by a manufacturer) actually included the word menarche (the term for a girl's first menstrual period). The illustrations were also problematic. A few of the booklets did not show any external genitalia, and the diagrams of the female reproductive organs often were presented separately from any bodily reference or body outline, which makes it difficult for a girl to imagine the scale of the system if she does not know where it is located. These booklets are used to educate, but girls who read them might learn more about stigma than about their physiology. One booklet stated out-right that "your main concern will probably be avoiding accidents with an appropriately absorbent pad, avoiding a wet feeling, and using a pad that doesn't show." The emphasis on secrecy and the potential for embarrassment is present in all of the booklets, and this emphasis may contribute to negative attitudes toward menstruation (Hoerster, Chrisler, and Gorman 2003).

Finally, menstrual stigma is perpetuated indirectly through silence. Menstruation is typically avoided in conversation (Kissling 1996), except under certain circumstances (for example, in private with female friends and relatives, in a health education or biology class, in a doctor's office). The majority of American adults surveyed for The Tampax Report (1981) agreed that menstruation should not be discussed in "mixed company," and many thought that it should not be discussed with the family at home. Williams (1983) found that $33 \%$ of the adolescent girls she surveyed would not talk about menstruation with their fathers, and nearly all of her participants agreed that girls should not discuss menstruation around boys. Even psychotherapists have reported experiencing discomfort when their clients want to discuss some aspect of menstruation (Rhinehart 1989). When teachers separate girls and boys to view films about puberty, and when mothers arrange one-to-one, private, "facts of life" talks with their daughters, they are conveying not only facts but guidelines for communication; they are marking menstruation "as a special topic, not one for ordinary conversation" (Kissling 1996, 495). Exclusive talks held in private convey the notion that menstruation is an embarrassing event that must be concealed from others and never discussed openly.

The communication taboo is supported by the existence of dozens of euphemisms for menstruation (Ernster 1975; Golub 1992), and these euphemisms can be found in cultures around the world. Ernster (1975) examined a collection of American expressions in the Folklore Archives at UC-Berkeley, and she grouped them into categories. For example, some refer to female visitors (for example, "My friend is here," 6), others to cyclicity (for example, "It's that time again," "my time of the month/moon," "my period," 6), illness or distress (for example, "the curse," "the misery," "I'm under the 
weather," 6), nature (for example, "flowers," "Mother Nature's gift," 7), redness or blood (for example, "I'm wearing red shoes today," "red plague," "red moon," "bloody scourge," 6-7), or menstrual products (for example, "on the rag," "riding the cotton pony," "using mouse mattresses," 6). Some of these euphemisms are still in common use today (Chrisler 2011), and new ones have no doubt been invented. If menstrual blood were not stigmatized, there would be no reason to call it anything other than its formal name: menstruation or the menses.

Although feminist scholars and activists (for example, Owen 1993; Stepanich 1992; Taylor 2003; Wind 1995; see also Bobel 2006, 2010) have tried to promote the celebration of menarche and menstruation, their positive messages may be overshadowed by the stigmatizing messages. Even those women and girls who do internalize the positive messages may find themselves confused about how to celebrate something that is supposed to be hidden. Their concerns about the consequences of doing so may be well-founded.

\section{Consequences of Stigma of Menstruation}

The stigma of menstruation has negative consequences for women's health, sexuality, well-being, and social status. One of the consequences most frequently noted in the literature is self-consciousness and hypervigilance associated with concerns about the revelation of one's menstrual status. Oxley (1998) found that both undergraduate women and women employed in the medical professions reported high levels of self-consciousness during menstruation. The behaviors they engaged in, and activities they avoided, reflected their determination to hide their menstrual status from others. For example, they wore baggy clothes and preferred tampons over pads. They avoided swimming and sexual activities during menstruation, often because of their concern about how others would respond to their menstrual blood. The researcher concluded that women might feel unattractive during their menses because menstrual cycle effects (for example, bloating, acne) indicate that they have been betrayed by their bodies. She argued that, in order for women to accept themselves every day of the month, cultures must change the way menstruation is viewed, and women themselves must take more control over the way they experience and feel about menstruation. In other words, women must resist, and cultures must reduce, the stigma.

The self-monitoring that women do to be sure that they look their best and that their menstrual status is hidden is related to the Foucauldian concept of self-policing (Foucault 1979). In a study of women who met criteria for severe PMS, Ussher (2004) found that women understood, experienced, and interpreted PMS symptoms as violations of the norms for "appropriate" femininity (for example, resisting the need to nurture others at one's own expense, displaying anger or annoyance one would usually conceal, experiencing 
one's body as unruly or out-of-control). Ussher argued that women's tendency to pathologize premenstrual experiences and to apply the PMS label to themselves represents a form of behavioral self-policing that allows them to distance themselves from their embodied selves in an effort to retain their femininity. Lapses in self-policing such as choosing to say "no" to others can then be blamed on the body rather than on the woman's own desires.

Objectification theory (Fredrickson and Roberts 1997) may help to explain why certain women are self-conscious about menstruation and go to unusual lengths to hide or eliminate their periods. Sexual objectification occurs when a woman feels that she is separate from, or represented by, parts of her body that are deemed sexual, such as her breasts and buttocks (Bartky 1990). In a culture where women's bodies routinely are sexually objectified, women themselves can internalize the sexual objectification of their bodies and view themselves through the lens of a critical male gaze. This self-objectification may lead women to monitor themselves constantly and to alter their self-presentation accordingly. Looking at the self this way has negative implications for psychological and sexual well-being (Muehlenkamp and Saris-Baglama 2002; Szymanski and Henning 2007; Tylka and Hill 2004). Goldenberg and Roberts (2004) have applied principles of terror management theory (Greenberg, Pyszczynski, and Solomon 1986) to explain pervasive negative attitudes toward menstruation. They argued that menstruation and other reproductive functions serves as reminders of the creaturely and therefore mortal nature of humans and women's proximity to nature. In an effort to allay existential angst about mortality, women may distance themselves from menstruation by adhering to cultural beauty standards. Both of these theories shed light on explanations for women's self-consciousness during menstruation and the social stigma attached to menstruation.

Feminist researchers have begun to consider the impact of self-objectification on attitudes toward menstruation, a bodily function that is incompatible with the view of the body as a sex object or as sexually available to others. Women who tend to self-objectify have been found to have particularly negative attitudes toward menstruation (Johnston-Robledo et al. 2007; Roberts 2004). Undergraduate women with higher self-objectification tendencies also have said that they would prefer not to have menstrual cycles (Johnston-Robledo et al. 2003) and reported positive attitudes toward the elimination of menstruation through the use of continuous oral contraception (that is, menstrual suppression; Johnston-Robledo et al. 2007). Thus, self-objectification may lead women to maintain a sense of global shame about multiple reproductive events, including menstruation, birthing, and breastfeeding (Johnston-Robledo et al. 2007). The shame and lowered self-esteem is psychologically damaging and may lead women to make reproductive decisions (for example, menstrual suppression, elective cesarean section, high-risk sexual behavior) that could have negative ramifications for their physical health (Andrist 2008; Johnston-Robledo et al. 2007; Kowalski and Chapple 2000; Schooler et al. 2005). 
Another consequence of menstrual stigma is observance of the sex taboo, that is, avoidance of intimate sexual relations during the menses. In a study of Latinas/os' sexual behavior during menstruation, the vast majority of women sampled reported that they avoided genital touching, oral sex, and sexual intercourse during menstrual bleeding; the men also reported that they avoided such activities with menstruating sexual partners (Davis et al. 2002). Why should women be bound by ancient fears about the uncleanliness of menstrual blood? Menstruation is a good time to have sex if the partners want to avoid pregnancy, and orgasm is said to relieve menstrual cramps (Boston Women's Health Book Collective 2005). Tanfer and Aral (1996) reported that women who had more lifetime sexual partners and more frequent sex were more likely to have sex during their menses than were women with fewer partners or less frequent sexual encounters. European American women were more likely than African American and Latin American women to say that they had had sex during their menses. Rempel and Baumgartner (2003) found that women who viewed menstruation as a normal and publicly acceptable event scored higher on a measure of personal comfort with sexuality and were more likely to have sexual relations during their periods than women who did not have such positive attitudes toward menstruation. On the contrary, Schooler et al. (2005) found that female undergraduate students who had feelings of shame regarding menstruation reported less sexual experience and more sexual risk-taking than did those who scored low on a measure of menstrual shame.

Finally, we believe that the stigma and taboo of menstruation both reflects and contributes to women's lower social status. In her classic, playful essay Gloria Steinem (1978) imagined that, if men could menstruate, menstruation would become an enviable, boastworthy, masculine event. She suggested, for example, that "sanitary supplies would be federally funded and free" (110). Her essay helps readers to understand that menstruation, as a biological, cultural, and political phenomenon, is only a "problem" because women do it.

Forbes et al. (2003) found that both male and female college students rated a menstruating woman as less sexy, more impure, and more irritable than women in general. Marván et al. (2008) asked college students in the U.S. and Mexico to list words that came to mind when they read the statements "A menstruating woman is ..." and "A premenstrual woman is ..." Only words that were mentioned by at least $50 \%$ of the 349 students were included in the analysis. Participants listed 92 negative words, which were grouped into the following categories: negative affect (for example, sad, frustrated), inactivity (for example, tired, weak), annoyance (for example, desperate, whining), instability (for example, unpredictable, moody), limitation/ rejection (for example, incapable, unlovable), and physical symptoms (for example, crampy, bloated). In contrast, they could think of only 55 neutral words (for example, cyclical, using pads) and 33 positive words (for example, active, beautiful). Despite the stigma, $50 \%$ of the participants thought that women are active and beautiful even at "that time of the month." 
Kowalski and Chapple (2000) investigated the consequences of the social stigma of menstruation on women's impression management behavior. They assigned young undergraduate women to be "interviewed" by a male confederate. Fifty percent of these women were menstruating at the time; the others were not. The male "interviewer" was aware of the menstrual status of $50 \%$ of the women in each group, and unaware of the menstrual status of the others. The menstruating participants interviewed by the man who was aware of their menstrual status believed that they had made a more negative impression on him than the women in the other three groups thought they had. They were also less concerned about making a positive impression on him than were the women in the other groups.

Roberts et al. (2002) primed menstrual status by manipulating whether their research assistant dropped a tampon or a hairclip where the participants in the study could see her do it. Both male and female undergraduate participants in the tampon condition later rated the research assistant as less competent and likeable than did the participants in the hairclip condition. Those who saw her drop the tampon also exhibited a tendency to sit farther away from her during the data collection than did those who saw her drop the hairclip. Results of this research show that the old ideas about stigma, taboo, and pollution are still operative. This work suggests that ruptures in women's concealment of their menstrual status lead to both social distancing and negative perceptions.

Clearly, more research is needed on how women's menstrual status may impact the way other people interact with and perceive them. However, it appears that women's desire and efforts to conceal their menstrual status may be well-founded. It would be interesting to study how people respond to women who actively subvert the cultural norm that menstruation should be hidden (for example, by discussing it openly or by washing out an alternative menstrual product, such as "the keeper," in a public restroom).

The self-monitoring for leaks and odors and the self-policing of behavioral or emotional clues to menstrual status is a waste of women's time and psychic energy that could be spent on more important or interesting pursuits. Young (2005) argued that menstruation is a source of oppression for women because of the shame attached to monthly bleeding and the challenges women face as menstruators in public spaces (such as work and school), and she argued that menstruation renders women "queer" in a society that identifies the male non-menstruator as the "normal" human. She suggested that menstruating women are, in effect, "in the closet" about their stigmatized menstrual status. "Social relations of somatophobia and misogyny continue to hold over women, in some circumstances, the threat of being 'outed' as menstruators, sometimes with serious consequences to their self-esteem or opportunities for benefits" (Young 2005, 113). Menstrual etiquette requires women to conceal their menstrual flow and to remain in the menstrual closet if they want to occupy public spaces along with men and nonmenstruating women (Laws 1990; Young 2005). But etiquette, like stigmatized conditions, depends on social, cultural, and historical context, and contexts can change. 


\section{Challenging/Resisting the Stigma of Menstruation}

What would happen if more women like Vanessa Tiegs and Petra Paul were willing to violate cultural norms? We are not suggesting that the menstrual cycle should be romanticized, that all women should celebrate every menses they experience, or that menstruation is central to womanhood or femininity. However, we do believe that the stigma of menstruation limits women's behavior and compromises their well-being. There are many different ways to eliminate the stigma, an important step toward "menstrual justice" (Kissling 2006, 126).

Culpepper (1992) suggested that simply talking about menstruation can create more positive attitudes, and she designed workshops aimed at raising women's "menstrual consciousness" to facilitate these conversations. Issues girls and women discussed in her workshops included names for menstruation, attitudes toward and stories about menstruation, and customs surrounding menstruation. If menstruation were discussed more openly, it might be easier for girls and women to acknowledge the positive aspects of menstruation and to challenge others when they make assumptions that all women hate and want to eliminate their periods. When researchers bother to ask, women are forthcoming about positive aspects of menstruation (Chrisler et al. 1994; Johnston-Robledo et al. 2003) and express concerns about eliminating monthly bleeding through continuous oral contraceptive use (Johnston-Robledo et al. 2003; Rose, Chrisler, and Couture 2008).

There is some evidence to suggest that adolescent girls are attempting to resist and challenge traditional norms about menstruation through social interactions that take place online among peers. Polak (2006) explored chat rooms, message boards, websites, and individual girls' homepages to learn more about the ways adolescent girls, or "gURLs," are constructing and experiencing menstruation. Her observations indicate that girls are "rewriting" the dominant negative menstruation narrative that was transmitted by both the feminine hygiene product industry and adults in their lives, such as their mothers and grandmothers.

Polak found that American adolescent girls use online spaces to talk frankly and openly about menstruation. For example, they answered each other's questions, validated each other's experiences, and encouraged one another to talk to their boyfriends about menstruation. Polak noted an absence of euphemisms and even some open dialogue about extremely stigmatized aspects of menstruation, such as the various colors and consistency of menstrual blood. She argued that these new online conversations about menstruation could facilitate girls' identity development and healthy embodiment. Although Polak acknowledged that this forum may leave out girls who do not have immediate access to computers, she did not consider how ethnicity, social class, or sexual orientation might have influenced girls' ideas, dialogue, or posts. It is interesting to consider that the relative anonymity of chat rooms can make it easier to discuss topics that are taboo in face-to-face conversations. 
However, face-to-face conversations about menstruation are also more common than they once were, especially among adolescent peers. Fingerson (2006) conducted a series of single-gender group interviews with predominantly European American adolescent boys and girls to explore their "menstrual talk." She concluded that some girls derived agency and empowerment from their menses. Themes that reflected this conclusion include girls' tendencies to embrace the challenge of managing their menstrual flow, to use and enjoy the privilege of having knowledge about their bodies that boys did not have, and to challenge the dominant and often negative social norms about menstruation. Although open talk about taboo topics is an important way to resist stigma, some of the girls attributed the empowerment derived from menstruation to their ability to embarrass boys with the mere mention of tampons or menstrual blood. Like the artists Tiegs and Paul, these girls are using shock to subvert the rule that menstruation must be hidden from the public square, but it is the stigma that allows them the power to embarrass boys at will. In a new print advertisement campaign for UKotex, consumers are encouraged to break the cycle of discomfort with tampons by being more open about them (Newman 2010). This goal is an admirable one, but the slogans for some ads (for example, "I tied a tampon to my keyring so my brother wouldn't take my car. It worked.") both challenge and reinforce the stigma of menstruation.

Girls living in the U.S. learn simultaneously that menstruation is important and natural and that they should hide and ignore it (Charlesworth 2001). How would this change if we celebrated menarche? Unlike Americans, individuals from countries around the world acknowledge this important rite of passage through various rituals such as a special gathering or party (Chrisler and Zittel 1998). The guest of honor may feel embarrassed initially, but a party could help her to realize that she, like other girls and women in her life, can overcome her embarrassment and have positive, even playful, attitudes toward menstruation. There are many organizations on the Internet, such as the Red Web Foundation (www.redwebfoundation.org) and First Moon (www.celebrategirls.org) that provide special kits to celebrate menarche and many other resources for raising menstrual consciousness.

The social stigma of menstruation can be challenged through the analysis of menstruation in popular culture. For example, social scientists have found that the popular press is rife with articles about menstruation that reinforce and perpetuate stigmatizing messages and provide inaccurate information about menstruation and premenstrual changes (Chrisler and Levy 1990; Johnston-Robledo, Barnack, and Wares 2006). Clearly, readers of popular magazines and newspapers should be encouraged to question and discuss what they read about menstruation in this material.

Others have resisted and challenged the stigma of menstruation through the creation of a menstrual counterculture. In his virtual museum, Harry Finley has collected women's stories about their experiences with 
menstruation as well as many images of advertisements, hygiene products, and other artifacts, which he displays on his website (www.mum.org). In her work on menstrual counterculture, Kissling (2006) noted that Finley's collection has a lot of educational potential because it challenges widely shared ideas about what is considered public and private. Artist/poet Geneva Kachman and several of her friends designated the Monday before Mother's Day as Menstrual Monday, a holiday to celebrate menstruation. She designs and distributes kits for this celebration including party blowouts made out of tampon applicators (www.moltx.org). Ani DiFranco's song, Blood in the Boardroom, is a rare example of popular music about menstruation. In her book Cunt, third-wave feminist Inga Muscio (2002) wrote about many different aspects of menstruation in a candid, humorous, and revolutionary way. Her writing on alternative menstrual products is especially compelling. Maybe it will inspire women to try an alternative to pads or tampons.

An important way to reduce stigma is social activism. Bobel $(2006,2008$, 2010) has written extensively about the history of menstrual activism as well as the myriad ways contemporary menstrual activists are drawing attention to the health and environmental hazards of menstrual hygiene products through organizations, political action, zines, and other publications. This kind of work could help people to appreciate the extent to which the social stigma of menstruation fuels and is perpetuated by consumerism. Finally, health care providers are beginning to recognize and promote menstruation as an important indicator, even a vital sign, of girls' and women's overall health (Diaz, Laufer, and Breech 2006; Stubbs 2008). The mission of the Project Vital Sign (www.projectvitalsign.org) campaign is to raise awareness about the role of menstruation in women's psychological and physical health with the ultimate goal of encouraging an open dialogue about menstruation between health care providers and their female patients. Efforts to politicize and/or normalize menstruation could go a long way toward reducing its stigmatized status.

\section{CONCLUSION}

The consideration of menstruation as a source of social stigma has promising implications for theory, research, and practice. We have demonstrated that menstruation fits all three of Goffman's (1963) categories and reviewed a significant body of literature that supports the stigmatized status of menstruation, the means through which the stigma is transmitted, and the consequences of the stigma. All of these areas are worthy of continued theoretical development and empirical investigation. Clearly, the stigmatized status of menstruation has detrimental consequences for girls' and women's self-esteem, body image, self-presentation, and sexual health. Feminist therapists, educators, and healthcare providers can consider ways to alleviate these negative consequences and to assist girls and women in their efforts to resist 
the stigma of menstruation. Equally important is the evidence that suggests that menstrual status, both actual and symbolic, primes and elicits negative attitudes toward women. Challenging the stigma of menstruation and learning to appreciate, or at least not loathe, menstruation may have a positive impact on girls' and women's well-being as well as their social status.

\section{Note}

1. "The Menstrual Mark: Menstruation as Social Stigma" by Ingrid Johnston-Robledo and Joan C. Chrisler was first published in 2013 in Sex Roles. 68 (1-2): 9-18. Reprinted with permission. No further reproduction or distribution of the material is allowed without permission from the publisher.

\section{REFERENCES}

Andrist, L. C. (2008). The Implications of objectification theory for women's health: Menstrual suppression and "maternal request" cesarean delivery. Health Care for Women International, 29, 551-565. https://doi. org/10.1080/07399330801949616.

Bartky, S. L. (1990). Femininity and domination: Studies in the phenomenology of oppression. New York: Routledge.

Berg, D. H., and Coutts, L. B. (1994). The extended curse: Being a woman every day. Health Care for Women International, 15, 11-22. https://doi. org/10.1080/07399339409516090.

Bobel, C. (2006). Our revolution has style: Contemporary menstrual product activists "Doing Feminism" in the third wave. Sex Roles, 56, 331-345. https://doi. org/10.1007/s11199-006-9001-7.

Bobel, C. (2008). From convenience to hazard: A short history of the emergence of the menstrual activism movement, 1971-1992. Health Care for Women International, 29, 738-754. https://doi.org/10.1080/07399330802188909.

Bobel, C. (2010). New Blood: Third-Wave Feminism and the Politics of Menstruation. New Brunswick: Rutgers University Press. Boston Women's Health Book Collective. (2005). Our bodies, ourselves: A new edition for a new era. New York: Simon \& Schuster.

Boston Women's Health Book Collective. (2005). Our Bodies, Ourselves: A New Edition for a New Era. New York: Simon \& Schuster.

Bramwell, R. (2001). Blood and milk: Constructions of female bodily fluids in Western society. Women \& Health, 34(4), 85-96. https://doi.org/10.1300/ j013v34n04_06.

Buckley, T., \& Gottlieb, A. (1988). Blood magic: The anthropology of menstruation. Berkeley, CA: University of California Press.

Charlesworth, D. (2001). Paradoxical constructions of self: Educating young women about menstruation. Women and Language, 24, 13-20.

Chesler, G. (Producer \& director). (2006). Period: The end of menstruation [Motion picture]. New York: Cinema Guild.

Chrisler, J. C. (2002). Hormone hostages: The cultural legacy of PMS as a legal defense. In L. H. Collins, M. R. Dunlap, \& J. C. Chrisler (Eds.), Charting a new course for feminist psychology (pp. 238-252). Westport: Praeger. 
Chrisler, J. C. (2007). PMS as a culture-bound syndrome. In J. C. Chrisler, C. Golden, \& P. D. Rozee (Eds.), Lectures on the psychology of women (pp. 154171). Boston: McGraw Hill.

Chrisler, J. C. (2008). 2007 Presidential address: Fear of losing control: Power, perfectionism, and the psychology of women. Psychology of Women Quarterly, 32, 1-12. https://doi.org/10.1111/j.1471-6402.2007.00402.x.

Chrisler, J. C. (2011). Leaks, lumps, and lines: Stigma and women's bodies. Psychology of Women Quarterly, 35, 202-214. https://doi. org/10.1177/0361684310397698.

Chrisler, J. C., \& Caplan, P. J. (2002). The strange case of Dr. Jekyll and Ms. Hyde: How PMS became a cultural phenomenon and a psychiatric disorder. Annual Review of Sex Research, 13, 274-306.

Chrisler, J. C., \& Levy, K. B. (1990). The media construct a menstrual monster: A content analysis of PMS articles in the popular press. Women \& Health, 16, 89-104. https://doi.org/10.1300/j013vl6n0207.

Chrisler, J. C., \& Zittel, C. B. (1998). Menarche stories: Reminiscences of college students from Lithuania, Malaysia, Sudan, and The United States. Health Care for Women International, 19, 303-312. https://doi. org/10.1080/073993398246287.

Chrisler, J. C., Johnston, I. K., Champagne, N. M., \& Preston, K. E. (1994). Menstrual joy: The construct and its consequences. Psychology of Women Quarterly, 18, 375-387. https://doi.org/10.1111/j.1471-6402.1994.tb00461.x.

Cicurel, I. E. (2000). The Rabbinate versus Israeli (Jewish) women: The Mikvah as a contested domain. Nashim: A Journal of Jewish Women's Studies, 3, 164-190.

Cochrane, K. (2009, October). It's in the blood. The Guardian. Retrieved from http:// www.guardian.co.uk/lifeandstyle/2009/oct/02/menstruation-feminist-activists.

Coutts, L. B., \& Berg, D. H. (1993). The portrayal of the menstruating woman in menstrual product advertisements. Health Care for Women International, 14, 179-191. https://doi.org/10.1080/07399339309516039.

Crocker, J., Major, B., \& Steele, C. (1998). Social stigma. In D. T. Gilbert, S. T. Fiske, \& G. Lindzey (Eds.), Handbook of social psychology (4th ed., Vol. 2, pp. 504-553). Boston: McGraw-Hill.

Culpepper, E. E. (1992).Menstrual consciousness raising: A personal and pedagogical process. In A. J. Dan \& L. L. Lewis (Eds.), Menstrual health in women's lives (pp. 274-284). Chicago: University of Illinois Press.

Davis, A. R., Nowygrod, S., Shabsigh, R., \& Westhoff, C. (2002). The influence of vaginal bleeding on the sexual behavior of urban, Hispanic women and men. Contraception, 65, 351-355. https://doi.org/10.1016/s0010-7824(02)00279-2.

Deaux, K., Reid, A., Mizrahi, K., \& Ethier, K. A. (1995). Parameters of social identity. Journal of Personality and Social Psychology, 68, 280-291. https://doi. org/10.1037/0022-3514.68.2.280.

Delaney, J., Lupton, M. J., \& Toth, E. (1987). The curse: A cultural history of menstruation (rev. ed.). Urbana: University of Illinois Press.

Diaz, A., Laufer, M., \& Breech, L. (2006). Menstruation in girls and adolescents: Using the menstrual cycle as a vital sign. Pediatrics, 118(5), 2245-2250.

Dovidio, J. F., Major, B., \& Crocker, J. (2000). Stigma: Introduction and overview. In T. F. Heatherton, R. E. Kleck, M. R. Hebl, \& J. G. Hull (Eds.), The social psychology of stigma (pp. 1-28). New York: Guilford. 
Erchull, M. J. (2010). Distancing through objectification? Depictions of women's bodies in menstrual product advertisements. Sex Roles. Advance online publication. https://doi.org/10.1007/s11199-011-0004-7.

Erchull, M. J., Chrisler, J. C., Gorman, J. A., \& Johnston-Robledo, I. (2002). Education and advertising: A content analysis of commercially produced booklets about menstruation. Journal of Early Adolescence, 22, 455-474. https://doi. org/10.1111/1471-6402.t01-2-00007.

Ernster, V. L. (1975). American menstrual expressions. Sex Roles, 1, 3-13. https:// doi.org/10.1007/bf00287209.

Fingerson, L. (2006). Girls in power: Gender, body, and menstruation in adolescence. Albany: State University of New York Press.

Forbes, G. B., Adams-Curtis, L. E., White, K. B., \& Holmgren, K. M. (2003). The role of hostile and benevolent sexism in women's and men's perceptions of the menstruating woman. Psychology of Women Quarterly, 27, 58-63. https://doi. org/10.1111/1471-6402.t01-2-00007.

Foucault, M. (1979). Discipline and punish: The birth of the prison. London: Penguin.

Frable, D. E. (1993). Dimensions of marginality: Distinctions among those who are different. Personality and Social Psychology Bulletin, 19, 370-380. https://doi. org/10.1177/0146167293194002.

Fredrickson, B. L., \& Roberts, T.-A. (1997). Objectification theory: Toward understanding women's lived experiences and mental health risks. Psychology of Women Quarterly, 21, 173-206. https://doi.org/10.1111/j.1471-6402.1997.tb00108.x.

Goffman, E. (1963). Stigma: Notes on the management of spoiled identity. New York: Simon \& Schuster.

Goldenberg, J. L., \& Roberts, T.-A. (2004). The beast within the beauty: An existential perspective on the objectification and condemnation of women. In J. Greenberg, S. L. Koole, \& T. Pyszcazynski (Eds.), Handbook of experimental existential psychology (pp. 71-85). New York: Guildford.

Golub, S. (1992). Periods: From menarche to menopause. Newbury Park: Sage.

Greenberg, J., Pyszczynski, T., \& Solomon, S. (1986). The causes and consequences of a need for self-esteem: A terror management theory. In R. F. Baumeister (Ed.), Public and private self (pp. 189-212). New York: Springer.

Heath, T.M. (2007). Vanessa Tiegs' menstrual blood painting journal: Art or biohazard? Retrieved from http://www.associatedcontent.com/article/280931/vanessa_ tiegs_menstrual_blood_painting.html.

Herek, G. M. (2009). Sexual stigma and sexual prejudice in the U.S.: A conceptual framework. In D. A. Hope (Ed.), Contemporary perspectives on lesbian, gay, and bisexual identities (pp. 65-111). New York: Springer.

Hoerster, K. D., Chrisler, J. C., \& Gorman, J. A. (2003). Attitudes toward and experiences with menstruation in the U.S. and India. Women \& Health, 38(3), 77-95. https://doi.org/10.1300/J013v38n03_06.

Houppert, K. (1999). The curse: Confronting the last unmentionable taboo. New York: Farrar, Straus, \& Giroux.

Johnston-Robledo, I., Ball, M., Lauta, K., \& Zekoll, A. (2003). To bleed or not to bleed: Young women's attitudes toward menstrual suppression. Women \& Health, 38(3), 59-75. doi:10.1300/J013v38n03_05. https://doi.org/10.1300/ j013v38n03_05. 
Johnston-Robledo, I., Barnack, J., \& Wares, S. (2006). "Kiss your period good-bye": Menstrual suppression in the popular press. Sex Roles, 54, 353-360. https://doi. org/10.1007/s11199-006-9007-1.

Johnston-Robledo, I., Sheffield, K., Voigt, J., \& Wilcox-Constantine, J. (2007). Reproductive shame: Self-objectification and young women's attitudes toward their bodies. Women \& Health, 46(1), 25-39. https://doi.org/10.1300/ j013v46n01_03.

Kissling, E. A. (1996). Bleeding out loud: Communication about menstruation. Feminism \& Psychology, 6, 481-504. https://doi.org/10.1177/ 0959353596064002.

Kissling, E. A. (2006). Capitalizing on the curse: The business of menstruation. Boulder: Rienner.

Kowalski, R. M., \& Chapple, T. (2000). The social stigma of menstruation: Fact or fiction? Psychology of Women Quarterly, 24, 74-80. https://doi. org/10.1111/j.1471-6402.2000.tb01023.x.

Laws, S. (1990). Issues of blood: The politics of menstruation. London: Macmillan.

Lee, J. (1994). Menarche and the (hetero)sexualization of the female body. Gender and Society, 8, 343-362. https://doi.org/10.1177/089124394008003004.

Lee, J., \& Sasser-Coen, J. (1996). Blood stories: Menarche and the politics of the female body in contemporary U.S. society. New York: Routledge.

Marván, M. L., Islas, M., Vela, L., Chrisler, J. C., \& Warren, E. A. (2008). Stereotypes of women in different stages of reproductive life: Data from Mexico and the U.S. Health Care for Women International, 29, 673-687. https://doi. org/10.1080/07399330802188982.

Merskin, D. (1999). Adolescence, advertising, and the idea of menstruation. Sex Roles, 40, 941-957. https://doi.org/10.1023/a:1018881206965.

Muehlenkamp, J. L., \& Saris-Baglama, R. N. (2002). Selfobjectification and its psychological outcomes for college women. Psychology of Women Quarterly, 26, 371-379. https://doi.org/10.1111/1471-6402.t01-1-00076.

Muscio, I. (2002). Cunt: A declaration of independence. Emeryville: Seal Press.

Newman, A. A. (2010, March 16). Rebelling against the commonly evasive feminine care ad. New York Times, p. B3.

Owen, L. (1993). Her blood is gold: Celebrating the power and mystery of menstruation. San Francisco: Harper.

Oxley, T. (1998). Menstrual management: An exploratory study. Feminism \& Psychology, 8, 185-191.

Polak, M. (2006). From the curse to the rag: Online gURLs rewrite the menstruation narrative. In Y. Jiwani, C. Steenbergen, \& C. Mitchell (Eds.), Girlhood: Redefining the limits (pp. 191-207). New York: Black Rose Books.

Raftos, M., Jackson, D., \& Mannix, J. (1998). Idealised versus tainted femininity: Discourses of the menstrual experience in Australian magazines that target young women. Nursing Inquiry, 5, 174-186. https://doi. org/10.1046/j.1440-1800.1998.530174.x.

Rempel, J. K., \& Baumgartner, B. (2003). The relationship between attitudes toward menstruation and sexual attitudes, desires, and behavior in women. Archives of Sexual Behavior, 32, 155-163. https://doi.org/10.1023/a:1022404609700.

Rhinehart, E. D. (1989, June). Psychotherapists' responses to the topic of menstruation in psychotherapy. Paper presented at the meeting of the Society for Menstrual Cycle Research, Salt Lake City, UT. 
Roberts, T.-A. (2004). Female trouble: The Menstrual Self-evaluation Scale and women's self-objectification. Psychology of Women Quarterly, 28, 22-26. https://doi. org/10.1111/j.1471-6402.2004.00119.x.

Roberts, T.-A., Goldenberg, J. L., Power, C., \& Pyszczynski. (2002). "Feminine protection:" The effects of menstruation on attitudes toward women. Psychology of Women Quarterly, 26, 131-139. https://doi.org/10.1111/1471-6402.00051.

Rose, J. G., Chrisler, J. C., \& Couture, S. (2008). Young women's attitudes toward continuous use of oral contraceptives: The effects of priming positive attitudes toward menstruation on women's willingness to suppress menstruation. Health Care for Women International, 29, 688-701. https://doi. org/10.1080/07399330802188925.

Rozin, P.,\&Fallon,A. E. (1987).Aperspective on disgust. Psychological Review, 94, 23-41. https://doi.org/10.1037/0033-295x.94.1.23.

Schooler, D., Ward, M. L., Merriwether, A., \& Caruthers, A. S. (2005). Cycles of shame: Menstrual shame, body shame, and sexual decision-making. Journal of Sex Research, 42, 324-334. https://doi.org/10.1080/00224490509552288.

Stallabrass, J. (2006). Contemporary art: A very short introduction. Oxford: Oxford University Press.

Steinem, G. (1978, October). If men could menstruate: A political fantasy. Ms., p. 110.

Stepanich, K. K. (1992). Sister moon lodge: The power and mystery of menstruation. Woodbury: Llewellyn.

Stubbs, M. L. (2008). Cultural perceptions and practices around menarche and adolescent menstruation in the United States. Annals of the New York Academy of Science, 1135, 58-66. https://doi.org/10.1196/annals.1429.008.

Szymanski, D. M., \& Henning, S. L. (2007). The role of selfobjectification in women's depression: A test of objectification theory. Sex Roles, 56, 45-53. https://doi. org/10.1007/s11199-006-9147-3.

Tampax report, The. (1981). New York: Ruder, Finn, \& Rotman. Tanfer, K., \& Aral, S. O. (1996). Sexual intercourse during menstruation and self-reported sexually transmitted disease history among women. Sexually Transmitted Diseases, 23, 395-401.

Tanfer, K., and S. O. Aral. 1996. Sexual Intercourse during Menstruation and SelfReported Sexually Transmitted Disease History among Women. Sexually Transmitted Diseases 23, 395-401.

Taylor, D. (2003). Red flower: Rethinking menstruation. Caldwell: Blackburn Press.

Tylka, T. L., \& Hill, M. S. (2004). Objectification theory as it relates to disordered eating among college women. Sex Roles, 51, 719-730. https://doi. org/10.1007/s11199-004-0721-2.

Ussher, J. M. (2004). Premenstrual syndrome and self-policing: Ruptures in self-silencing leading to increased self-surveillance and blaming of the body. Social Theory \& Health, 2, 254-272. https://doi.org/10.1057/palgrave.sth.8700032.

Williams, L. R. (1983). Beliefs and attitudes of young girls regarding menstruation. In S. Golub (Ed.), Menarche: The transition from girl to woman (pp. 139-148). Lexington: Lexington Books.

Wind, L. H. (1995). New moon rising: Reclaiming the sacred rites of menstruation. Chicago: Delphi Press.

Young, I. M. (2005). On female body experience: "Throwing like a girl” and other essays. New York: Oxford University Press. 
Open Access This chapter is licensed under the terms of the Creative Commons Attribution 4.0 International License (http://creativecommons.org/licenses/ by $/ 4.0 /)$, which permits use, sharing, adaptation, distribution and reproduction in any medium or format, as long as you give appropriate credit to the original author(s) and the source, provide a link to the Creative Commons license and indicate if changes were made.

The images or other third party material in this chapter are included in the chapter's Creative Commons license, unless indicated otherwise in a credit line to the material. If material is not included in the chapter's Creative Commons license and your intended use is not permitted by statutory regulation or exceeds the permitted use, you will need to obtain permission directly from the copyright holder. 